\title{
Plant Selection and Population Trend of Spittlebug Immatures (Hemiptera: Aphrophoridae) in Olive Groves of the Apulia Region of Italy
}

\author{
Crescenza Dongiovanni, ${ }^{1}$ Vincenzo Cavalieri, ${ }^{2}$ Nicola Bodino, ${ }^{3}$ Daniele Tauro, ${ }^{1}$ \\ Michele Di Carolo, ${ }^{1}$ Giulio Fumarola, ${ }^{1}$ Giuseppe Altamura, ${ }^{2}$ Cesare Lasorella, ${ }^{4}$ and \\ Domenico Bosco ${ }^{3,5,6, \odot}$
}

\begin{abstract}
'Centro di Ricerca, Sperimentazione e Formazione in Agricoltura Basile Caramia, Via Cisternino, 281, 70010 Locorotondo (Bari), Italy, ${ }^{2}$ CNR - Istituto per la Protezione Sostenibile delle Piante, SS Bari, Via Amendola 122/D, 70126 Bari, Italy, ${ }^{3}$ CNR —Istituto per la Protezione Sostenibile delle Piante, Strada delle Cacce, 73, 10135 Torino, Italy, ${ }^{4}$ Dipartimento di Scienze Agro-Ambientali e Territoriali, Università degli Studi di Bari Aldo Moro, Via Amendola, 165/A, 70126 Bari, Italy, ${ }^{5}$ Dipartimento di Scienze Agrarie, Forestali e Alimentari, Università degli Studi di Torino, Largo Paolo Braccini, 2, 10095 Grugliasco, Italy, and ${ }^{6}$ Corresponding author, e-mail: domenico.bosco@unito.it
\end{abstract}

Subject Editor: John Trumble

Received 7 July 2018; Editorial decision 14 August 2018

\begin{abstract}
The xylem-limited bacterium Xylella fastidiosa Wells is the causal agent of severe diseases of several cultivated and wild plants. It is transmitted by xylem-sap feeder insects, such as spittlebugs (Hemiptera: Cercopoidea) and sharpshooters (Hemiptera: Cicadellinae). A dramatic epidemic of $X$. fastidiosa subspecies pauca sequence type 53 is currently affecting a large area of the Apulia Region of Italy, where it is spread by Philaenus spumarius L. adults within olives. In 2015 and 2016, field surveys were carried out in Apulian olive groves to investigate host plant selection of spittlebug nymphs, to identify the main plant species that can act as reservoirs of the vectors. Two different sampling methods were used: randomized plant sampling and quadrats sampling. Host plant selection by $P$. spumarius and Neophilaenus campestris (Fallén) nymphs was estimated using Manly's selection index. The botanic families presenting the highest number of plants infested by $P$. spumarius nymphs were Asteraceae, Fabaceae, and Apiaceae. Nymphs of $P$. spumarius were sampled on 72 plant genera, and among the most common 25 genera, Sonchus, Knautia, Glebionis, Urospermum (Asteraceae), Medicago, Vicia, Melilotus (Fabaceae), and Daucus (Apiaceae) were the ones selected preferentially, according to Manly's index results. Populations of $P$. spumarius nymphs peak in early April, with densities ranging between 10 and 40 nymph $/ \mathrm{m}^{2}$, were about 10 -fold those of $N$. campestris. Plant infestation rate by spittlebug nymphs in 2016 was significantly higher in olive groves located in Lecce province (infected area) than those situated in Bari province (noninfected area).
\end{abstract}

Key words: insect vectors, Cercopoidea, host plant, olive

Spittlebugs are xylem-sap feeder hemipteran insects belonging to the families Aphrophoridae, Cercopidae, and Clastopteridae (this latter family is absent in Europe). Nymphs of 'true' spittlebugs (Aphrophoridae) develop above ground and are well known for their spittle masses produced by mixing excretion, secretion produced by abdominal glands and air bubbles introduced via caudal appendages, providing a protection from both predation and solar radiation (Whittaker 1970, Chen et al. 2018, Cornara et al. 2018). Immatures develop through five nymph instars that, with few exceptions, feed on herbaceous plants (Halkka et al. 1977, Nickel and Remane 2002). The adults, generally long living, can continue to either feed on herbaceous plants or move to the canopy of trees and shrubs. This host shifting behavior is almost obligatory under the conditions of warm, dry Mediterranean areas, where the ground cover vegetation almost completely disappears during summer and only woody plants can sustain feeding of adults (Bodino et al. 2017).

The spittlebug Philaenus spumarius L. (Hemiptera: Aphrophoridae) is by far the most common and widespread xylem-sap feeder insect in Europe and locally can reach high densities (Whittaker 1973, de Jong 2014, Rodrigues et al. 2014). It is highly polyphagous, both during nymphal and adult stage, and adults are polymorphic for dorsal pigmentation (Halkka et al. 1967, Drosopoulos 2003, Borges et al. 2018). Females of P. spumarius undergo an ovarian parapause (Witsack 1973), and even if they can 
mate soon after emergence (Wiegert 1964, Cornara et al. 2018), they do not mature eggs. At the end of the summer-beginning of autumn, depending on the latitude, adults are back to the herbaceous ground cover and females start maturing and lay eggs, generally on dry leaves or plant material (e.g., straw) on the soil (Weaver and King 1954).

$P$. spumarius has been poorly studied during the last $50 \mathrm{yr}$, and research was focused mainly on its polymorphism and its importance in meadow ecosystems. Recently, after the repeated discoveries of the bacterium Xylella fastidiosa Wells in Europe, and the associated epidemic disease of olive trees in the Apulian Region of Italy, that already spread to an area of at least $5,000 \mathrm{~km}^{2}$ encompassing one to three million olive trees, interest on spittlebugs has dramatically increased.

Indeed, xylem-sap feeder insects (namely, sharpshooters in the family Cicadellidae and subfamily Cicadellinae and spittlebugs in the family Aphrophoridae) are well-known vectors of the xylemlimited plant pathogenic bacterium X. fastidiosa (Redak et al. 2004). The transmission of $X$. fastidiosa by insects is peculiar in that it does not require a latent period, yet the bacteria are persistently transmitted. Bacteria are restricted to the foregut (namely, the precibarium) and do not infect systemically the insect body (Hill and Purcell 1995, Almeida et al. 2005). The currently available phylogenetic data on $X$. fastidiosa indicate that the invasive strain in Apulia belongs to the $X$. fastidiosa subspecies pauca, sequence type (ST) 53 , and was possibly introduced from Costa Rica (Giampetruzzi et al. 2017). Furthermore, other X. fastidiosa subspecies/STs have been recently discovered in France and Spain (EFSA 2018). The presence of $X$. fastidiosa in Mediterranean regions prompted research on the insect vectors of the bacterium in the new infected areas, where a number of potential $X$. fastidiosa vectors are present throughout the Mediterranean basin (EFSA 2015). Preliminary investigations pointed out that, among Aphrophoridae, two species were common in the infected area of Lecce province, P. spumarius and Neophilaenus campestris (Fallén) (Hemiptera: Aphrophoridae) (Elbeaino et al. 2014, Ben Moussa et al. 2016). Attempts to identify vectors of the CoDIRO strain of X. fastidiosa in Apulia Region were successful, and field-collected P. spumarius were found transmitting X. fastidiosa to periwinkle (Saponari et al. 2014). Cornara et al. (2017a) confirmed the role of $P$. spumarius and demonstrated that spittlebugs collected in heavily infected olive groves transmitted $X$. fastidiosa to olive, oleander, and periwinkle plants. Finally, the olive-to-olive transmission by $P$. spumarius was achieved under fully controlled transmissions, although $N$. campestris failed to transmit under the same experimental conditions (Cornara et al. 2017b). Very recently, the X. fastidiosa transmission competence of $N$. campestris and Philaenus italosignus Drosopoulos \& Remane (Hemiptera: Aphrophoridae) has been proved under experimental conditions (Cavalieri et al. 2018).

The spread of $X$. fastidiosa diseases is the outcome of complex biotic and abiotic interactions, and it is hard to predict; however, the speed of spread depends, among other factors, on the population level of competent vectors. In the olive groves, the main factor regulating vector population level is the availability of a ground cover and its species composition that can be more or less favorable/attractive to spittlebugs. In spite of a rich literature reporting host plants of P. spumarius nymphs, e.g., Weaver and King (1954) provided a list of more than 200 plant species, no information is available on host plant preference of this species in Mediterranean region. Similarly, for Neophilaenus spp., data from literature indicate that nymphs are associated with gramineous plants (Whittaker and Tribe 1998), but information on host plant preference among these latter is not available. Therefore, the aim of the present work was to describe host plant selection of spittlebug nymphs under field conditions in
Apulian olive groves located both inside and outside the $X$. fastidios $a$-infected area, thus identifying those plants that, both inside and nearby olive groves, can act as reservoirs of the vectors.

\section{Materials and Methods}

Monitoring of spittlebug nymphs was carried in Apulian olive groves during Spring 2015 and 2016. Three survey campaigns were carried out using two different sampling methods: 1) randomized plant sampling, consisting in the examination of about 100 individual plants per each of the most common plant genera found in the different olive orchards (range 8-24 plant genera per olive grove), looking for spittle masses of P. spumarius nymph and 2) quadrats sampling, consisting in visual counting of spittlebug nymphs, both $P$. spumarius and $N$. campestris, in 12 samples $\left(1 \mathrm{~m}^{2}\right.$ each) randomly distributed along the two diagonals of olive orchards. The two different sampling methods were applied in the first year of investigation to obtain information on host plant selection (with method 1) and population abundance and nymphal stage structure over time (with method 2). In the second year, we focused only on host plant selection on a large number of sites, and therefore, the randomized plant sampling method was chosen and applied only once during the nymphal period. During spring 2015, six olive groves (provinces of Bari, Brindisi, Lecce, and Taranto) were inspected following method 1 and three (province of Lecce) with method 2; in all the nine olive groves, surveys were carried out three to four times during spring, from late March to early May. In Spring 2016, 42 olive groves located in Bari, Brindisi, and Lecce provinces were inspected employing method 1 , and all olive orchards were sampled only once during March-April. All the sampling sites are reported in Fig. 1. In all the olive groves, the spittlebug population was undisturbed, as neither soil tilling against nymphs, nor insecticides against adults, was applied. During each survey, plants were identified at the genus level according to Pignatti (1997) and checked for the presence of spittles, and all plants carrying at least one spittle were considered infested. Identification of Poaceae genera was not always possible (e.g., in the preflowering stage), and therefore, host plants were classified as Poaceae spp. During visual counting, the nymphal instars of Philaenus were morphologically determined according to Weaver and King (1954). Neophilaenus nymphs were identified and distinguished from those of $P$. spumarius according to Vilbaste (1982). Analyses of host plant selection for $P$. spumarius nymphs were carried out separately for each survey and data from different sampling dates in 2015 surveys were pooled. Preimaginal population dynamics were analyzed using only the 2015 quadrat samplings data.

\section{Data Analysis}

Host plant selection by P. spumarius and Neophilaenus spp. nymphs was estimated using infestation percentage, both total and mean $\left({ }_{ \pm} \mathrm{SE}\right)$, and Manly's selection index for a constant prey population (Manly et al. 1994), calculated for each plant genus. To allow a clear comparison of the results, the number and percentage of infested plants were pooled by olive grove for all the three surveys; thus, the effect of date on plant selection was not investigated. Manly's selection index links the proportion of infested individual plants (positive individual plants) with the plant food supply (number of plants surveyed). An index value above or below the ' $1 / m$ threshold' ( $m$, number of available plant genera) indicates a positive or negative selection, respectively. Therefore, a value significantly above the $1 / m$ means that the plant genus is selected disproportionately high compared with its abundance and thus is preferred; on the contrary, if it is below $1 / m$, the plant genus tends to be avoided. However, it is 


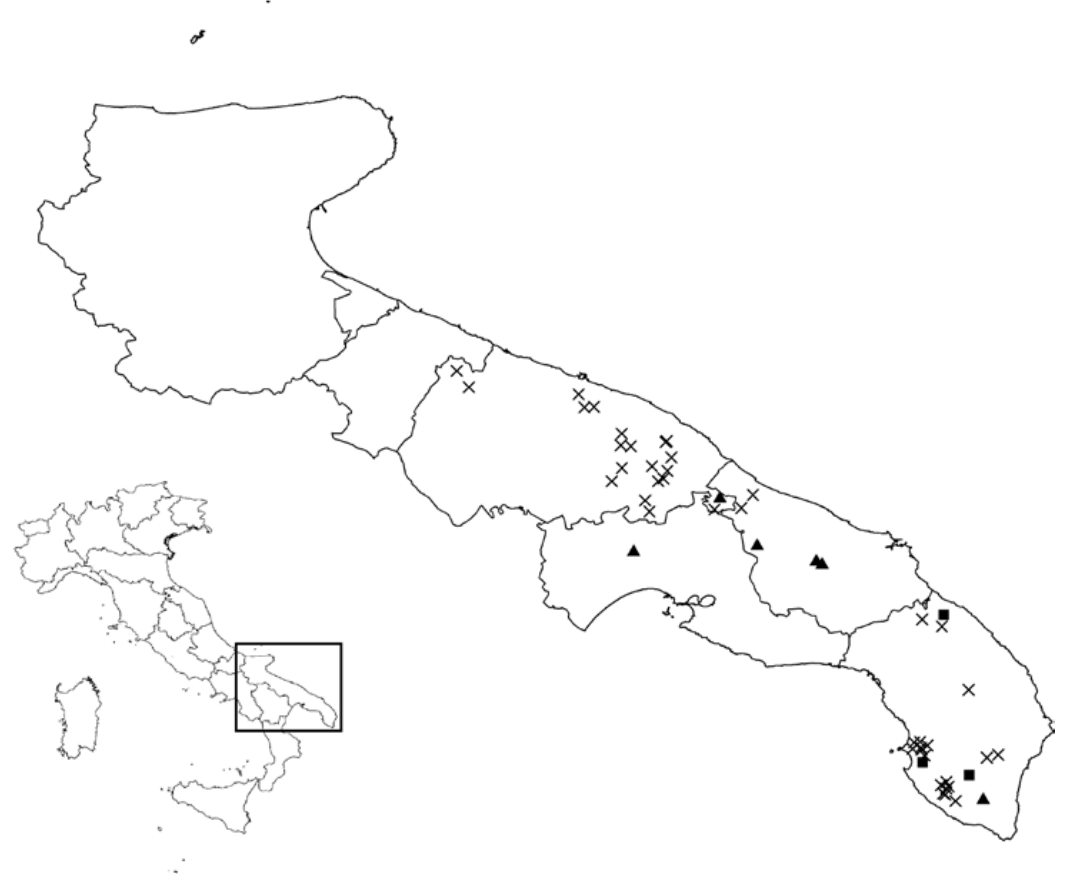

Fig. 1. Locations of Apulian olive groves surveyed for spittlebugs during the $2015-2016$ samplings. $\mathbf{D}=2015$ quadrat sampling; $\boldsymbol{\Delta}=2015$ plants sampling; $\times=2016$ plants samplings.

noteworthy that the values for the selection index are normalized, so that their sum is constant $(\Sigma=1)$, this means that if one plant genus is preferred, another one has to be avoided. To test whether the mean value of Manly's index was significantly different from $1 / m$ threshold, a percentile bootstrapped ( $n=9,999), 20 \%$ trimmed means, one sample $t$-test was performed (function trimpb, WRS package, $\mathrm{R}$ Core Team 2017).

Differences in population density over season between $P$. spumarius and Neophilaenus spp. during 2015 quadrats sampling were analyzed using a mixed generalized linear model (GLMM; function glmer, package $l m e 4, \mathrm{R}$ Core Team 2017). Data were modeled using Poisson distribution with log link function, with spittlebug species and olive grove as fixed factors, whereas date was considered as a random effect factor. Differences within groups were tested using a Holm-Sidak test for pairwise comparisons. The proportion of overall infested plant per olive orchard in 2016 plant samplings was analyzed for differences between olive groves located in Bari or Lecce province, through generalized linear model (GLM), assuming binomial distribution; model estimates were corrected for overdispersion $(\mathrm{glm}$ link function $=$ quasi-binomial $)$.

\section{Results}

\section{Host Plant Selection}

The surveys carried out in 2015 and 2016 included 90 unique genera of herbaceous plants, for a total of 145,821 examined plants and 8,619 infested plants (overall infestation rate $5.9 \%$ ), belonging to 72 different genera (Supp Table S1 [online only]). The botanic families accounting for the majority of sampled plants were Asteraceae, Poaceae, Fabaceae, and Rubiaceae. The botanic families presenting the highest number of plants infested by $P$. spumarius nymphs were Asteraceae $(3,319$ infested plants; $38.51 \%$ of total infested plants), Fabaceae $(2,423$; $28.11 \%)$, Apiaceae $(760 ; 8.82 \%)$, and Poaceae $(383 ; 4.44 \%)$.

To avoid biases in plant selection given by rare plant taxa with high infestation rates, but little ecological value, only the 25 most common plant genera (i.e., with more individual plants sampled) were used for host plant selection analyses. The 25 most common plant genera represented $67.8 \%$ of total plants sampled and were ranked based on total infested plants sampled across the three surveys (Table 1; the complete list of sampled plant genera, together with the percentage of infested plants, is reported in Supp Table S1 [online only]).

Sonchus was the plant genus presenting the highest number of infested plants by $P$. spumarius nymphs in all the three surveys. In the 2015 quadrats sampling, Sonchus was the prevalent host plant of meadow spittlebug, with an average infestation rate of $44 \%$, and representing almost $21 \%$ of the total infested plants. Also, during the 2015 plants sampling, Sonchus was the plant genus with the highest mean percentage of total infested plants (14.3\%), followed by Knautia $(11.4 \%)$. The 2016 plants samplings involved a much higher number of olive groves, with different plant composition and environmental conditions, and therefore showed a greater variety in the most infested plant genera. Actually, over the 42 olive groves, Vicia, Medicago, and Knautia presented mean infestation rates similar to the one registered for Sonchus (Table 1).

Taking into consideration all the plant genera sampled across the three surveys (Supp Table S1 [online only]), some relatively uncommon plants (i.e., not included in the 25 most common plant taxa) showed very high rates of infestation, sometimes higher than Sonchus, e.g., Foeniculum (23\%), Lathyrus (23\%), Galactites (21\%), and Rosmarinus (15\%).

The Manly's selectivity index results concerning the 25 most common plant genera supported the positive selection of Sonchus by preimaginal instars of $P$. spumarius in all the three surveys (Fig. 2), but also showed other common plant genera preferentially selected during the different surveys, such as Knautia, Glebionis, and Daucus. However, the host plant selection results were not always similar between the different surveys, given also the differences in sampling methodology and number of olive groves sampled (see Materials and Methods). In the 2016 survey, that included the highest number of 


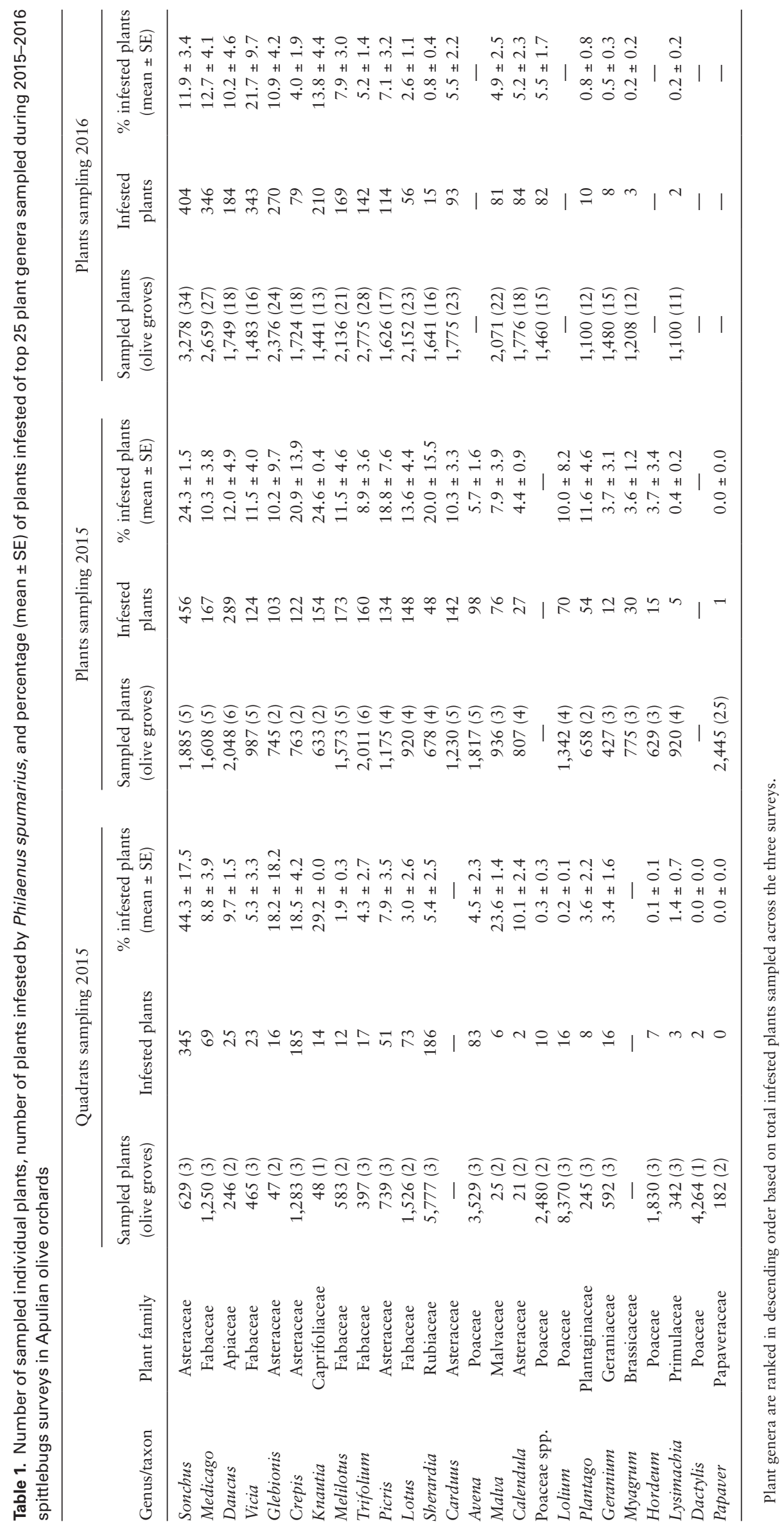


olive orchards (42), the Fabaceae Medicago, Vicia, and Melilotus, the Asteraceae Glebionis and Urospermum, Apiaceae Daucus and Poaceae presented mean index values significantly higher than the $1 / m$ threshold, meaning that they were preferentially selected (Fig. 2c). Crepis was among the plant genera selected positively during 2015 quadrats samplings (Fig. 2a), whereas Lathyrus, Picris, Melilotus, Lotus, and Plantago were also selected preferentially during 2015 plant samplings (Fig. 2b).

Some common plant genera appeared to be negatively selected, or avoided, by spittlebugs. Several Poaceae, Lysimachia, Raphanus, Papaver, Fumaria, Geranium, and Sherardia presented significantly lower values of the Manly's index compared with the $1 / m$ threshold (Fig. 2); these results were confirmed by the low mean infestation rates registered for these plant taxa (Table 1). Poaceae, considered as whole, presented a relatively high value of the Manly's index (0.072) only during 2016 plants samplings (Fig. 2c).

Neophilaenus spp. nymphs were sampled and identified only during the 2015 quadrats survey, with a total of 267 nymphs
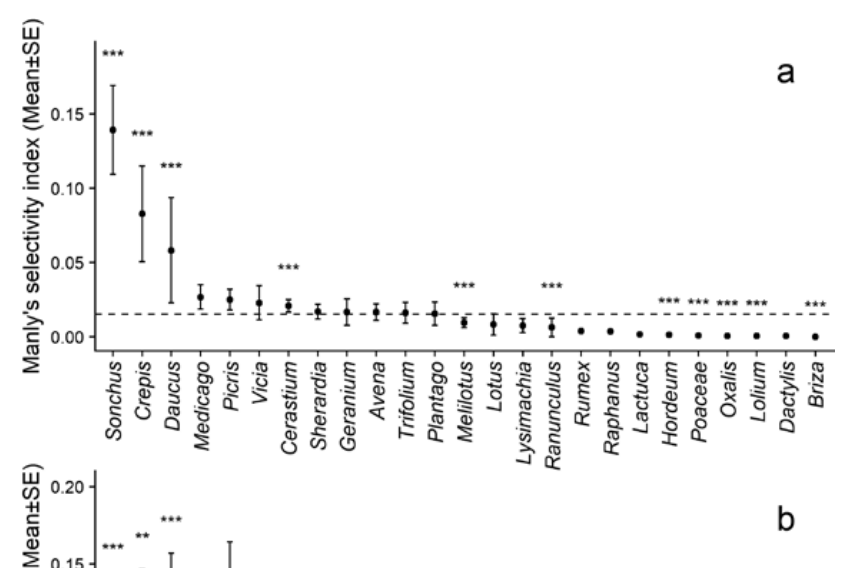

b

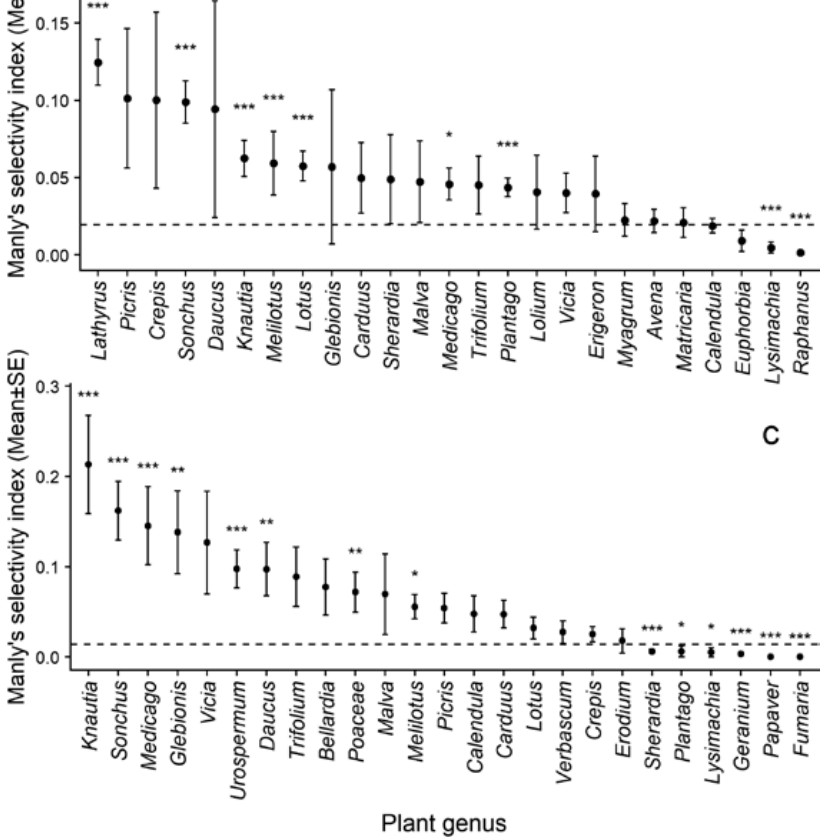

Fig. 2. Manly's selection indexes (mean \pm SE) for the top 25 plant genera for abundance in the three surveys, arranged for decreasing mean values of the index (a, 2015 quadrats sampling; b, 2015 plants sampling; c, 2016 plants samplings). The dashed lines display the $1 / m$ thresholds, where $m$ is the number of available plant genera; values exceeding this threshold indicate positive selection, whereas the values below indicate negative selection for the respective plant genera. sampled that accounted for $9.97 \%$ of the total spittlebug population. Poaceae were by far the most selected host plants, with $94.01 \%$ of total Neophilaenus spp. nymphs located on plants belonging to this family. In detail, Avena was the plant genera on which most of the nymphs were found $(52.81 \%$ of the total nymphs), followed by Hordeum (16.1\%), Lolium (15.36\%), and Dactylis (5.99\%). Avena and Lolium were the only plant genera with Manly's selectivity index values significantly above the $1 / m$ threshold (0.015) (Avena: mean $=0.47$ [confidence interval (CI) 0.222-0.844]; Lolium: mean $=0.07$ [CI 0.029-0.126]). Host plants belonging to other families were seldom selected, with only seven Neophilaenus spp. nymphs sampled on forbs throughout the season.

\section{Population Abundance of Spittlebug Nymphs}

During the 2015 quadrats survey, P. spumarius and Neophilaenus spp. nymphs showed different populations abundance throughout the season. In total, 2,409 P. spumarius and 267 Neophilaenus spp. immatures were sampled, with an overall Philaenus/Neophilaenus ratio of 9.02. Densities of $P$. spumarius nymphs were higher than Neophilaenus spp. throughout the season in all the three olive groves surveyed (GLMM: $F=885.63 \mathrm{df}=1, P<0.001$ ). The difference between the two spittlebug species was particularly high in the olive grove located in Surbo, where only 31 grass spittlebugs were sampled and the ratio was 35.2 (Fig. 3c). Excluding the last sampling date (when spittlebug abundances were really low in all the olive groves, as most of insects were already emerged as adults), P. spumarius densities throughout the season were significantly different among olive groves,

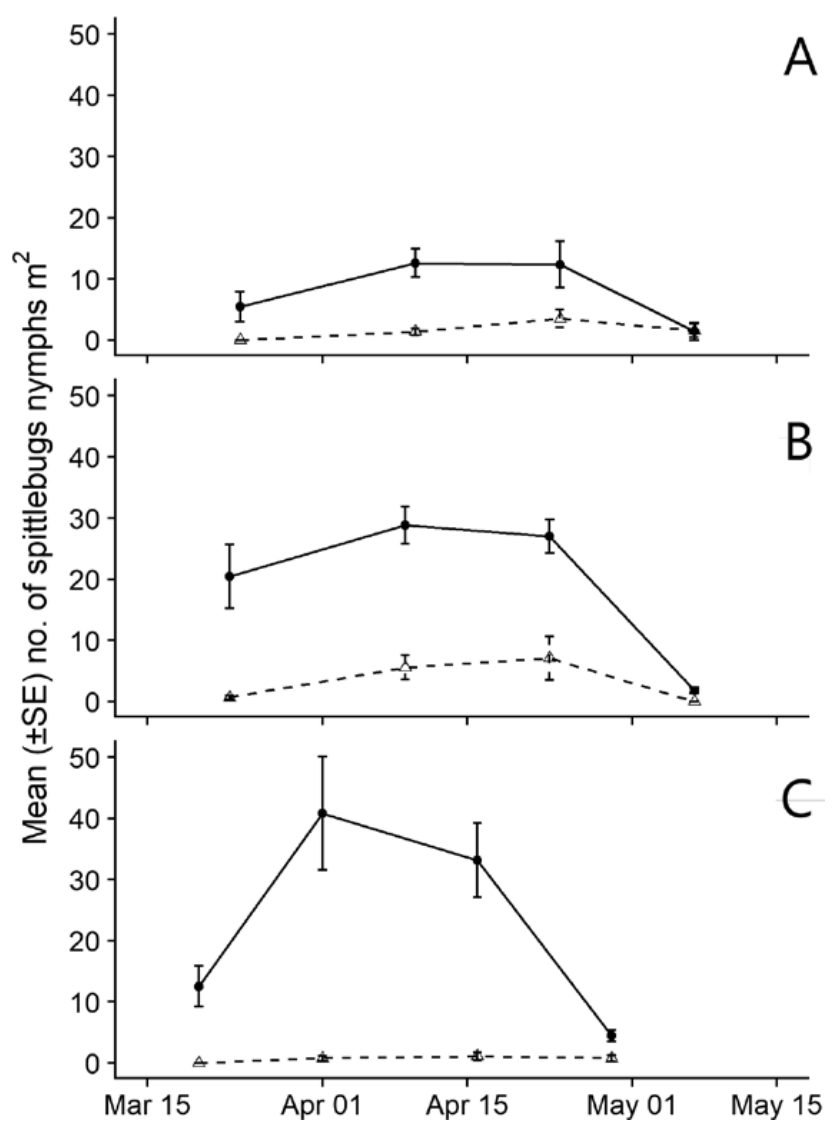

Fig. 3. Population abundance of spittlebugs nymphs (mean \pm SE) in 2015 quadrat samplings in three olive groves located in Ruffano (a), Gallipoli (b), and Surbo (c). Continuous line, Philaenus spumarius; dashed line, Neophilaenus campestris. 
with population in Ruffano orchard significantly lower than the populations observed in the other two olive groves (GLMM: $F=13.31$, $\mathrm{df}=2, P=0.001)$. However, including all sampling dates, densities were not significantly different among olive groves (GLMM: $F=2.05$, $\mathrm{df}=2, P=0.358)$. The first sampling dates, around 20-25 March, were carried out when second nymphal instars were prevalent (Fig. 4). During the last samplings in late April to early May, the nymphal populations were very low (Fig. 3). In the three sites of the Lecce province, nymphs disappeared by the end of April until beginning of May in 2015 (Fig. 3). Populations of Neophilaenus spp. seemed to follow a similar trend, although the very low population levels did not allow an accurate description of the populational dynamics.

The phenological progression of nymphal stages occurred as a series of overlapping distributions, except for the last sampling in late April to early May, when only fifth instar nymphs were collected. First and second instars nymphs were found until the first week of April, whereas third instar nymphs were present until midApril. Fourth instar nymphs were collected during all the sampling span, with a peak in the first half of April; fifth instar represented most of the nymphs in late April to early May. The high degree of overlapping of the different nymphal stages is well described by the coexistence of all the five stages during the first half of April in all the three olive groves (Fig. 4).

Plant infestation rate by spittlebug nymphs in 2016 was significantly higher in olive groves located in Lecce province $(6.85 \pm 1.18 \%)$ than those situated in Bari province $(2.08 \pm 0.51 \%$; GLM: $\left.\chi^{2}=14.63, \mathrm{df}=1, P<0.001\right)$.

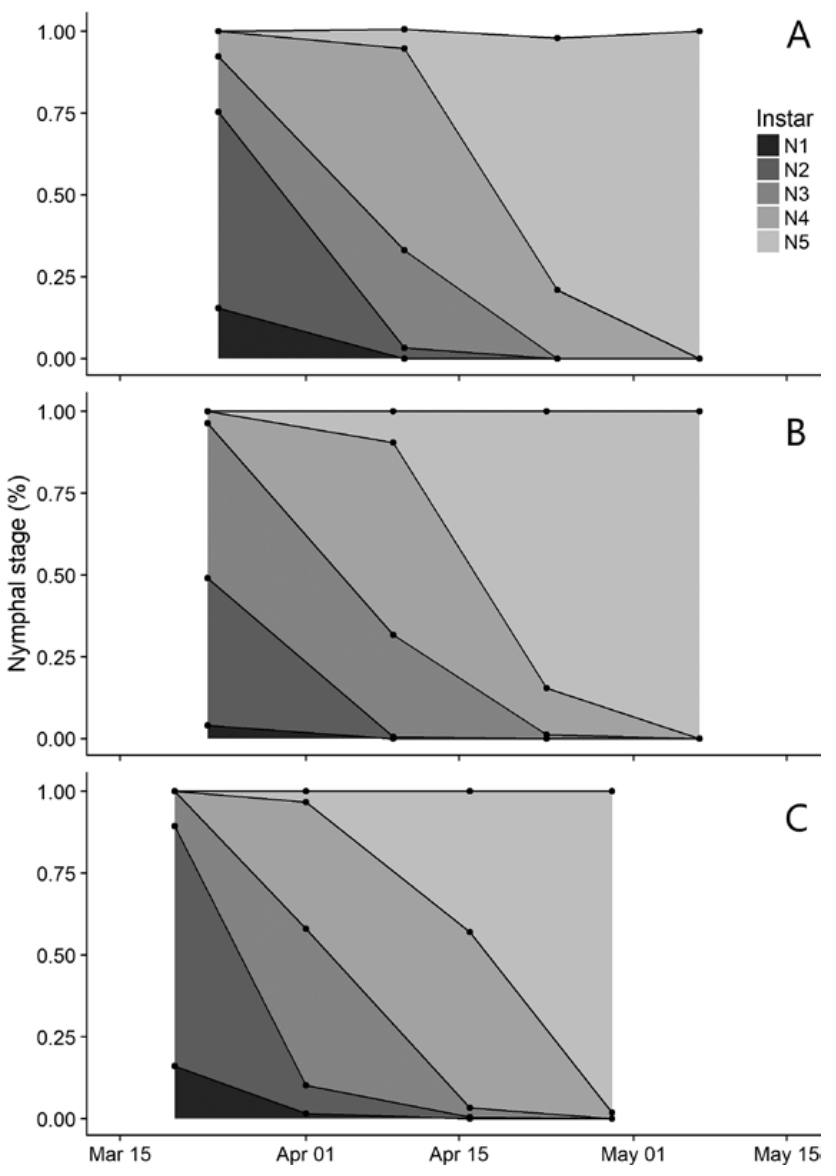

Fig. 4. Nymphal stages structure of Philaenus spumarius over the season in 2015 quadrat samplings in three olive groves located in Ruffano (a), Surbo (b), and Gallipoli (c).

\section{Discussion}

The host plant selection and nymph population abundance of the vectors $P$. spumarius and $N$. campestris in the herbaceous ground cover of olive groves have been described in the Apulia Region, including the area where $X$. fastidiosa subsp. pauca ST53 is epidemic on olive.

Host plant selection has been investigated using two different sampling methods, randomized plant sampling and quadrats sampling on a large number of sites over two consecutive years. The results of the different surveys are quite consistent, although ranking of preferred host plants slightly differs because of the different plant composition of herbaceous covers in the different olive groves. Some genera of the families Asteraceae (mainly Sonchus, Crepis, and Picris), Fabaceae (mainly Medicago, Vicia, and Lathyrus), and Apiaceae (Daucus and Foeniculum) are preferentially selected by P. spumarius, whereas Poaceae (mainly Avena, Hordeum, and Lolium) are preferentially selected by N. campestris. Due to the very high polyphagy of the meadow spittlebug, it is interesting to identify, besides the preferred plants, those species that are negatively selected. Among these latter, some Poaceae, Oxalis (Oxalidaceae), Lysimachia (Myrsinaceae), Sherardia (Rubiaceae), Geranium (Geraniaceae), Papaver (Papaveraceae), Fumaria (Fumariaceae), and Raphanus (Brassicaceae) were avoided by P. spumarius nymphs (i.e., significantly less infested compared to their abundance in the sample area). Our results confirm that preimaginal instars of the meadow spittlebug tend to prefer forbs (herbs other than grasses), as often reported in literature (e.g., Weaver and King 1954, Halkka et al. 1967, Cornara et al. 2018), but also show, only during the largescale survey of 2016, a positive selection for grasses (Poaceae). This outcome can have different explanations: 1) some common gramineous species can be relatively attractive for later instar nymphs, such as Sorghum and Avena, possibly because of their structure, providing wide leaf axils and protected feeding sites (McEvoy 1986); 2) seasonality (e.g., premature drying of dicots and unavailability of preferred host plants); 3) uneven sprouting of plants following grass cuttings; and 4) impossibility to separate the effect of site and date of inspection, given that only one sample was carried out per each olive grove. On the contrary, N. campestris nymphs appear strictly associated with Poaceae, as reported in the literature (Halkka et al. 1967, Whittaker 1973, Nickel and Hildebrandt 2003).

Host plant association of $P$. spumarius nymphs is not fully static, as nymphs, especially later instars, show some dispersal capability, not only within, but also among plants (author's observation). This mobility is limited, and estimated to a maximum of $60 \mathrm{~cm}$ by Halkka et al. (1967), but results of host plant association can be partly biased by the age of the nymph population as early instar nymphs tend to prefer plants with basal rosettes (Bodino et al. 2017) and later instar can probably feed on a wider range of plants (Hoffman and McEvoy 1985). However, the present study describes the host plant selection by $P$. spumarius nymphs on a relatively large geographical scale and therefore could not be focused on plant association of age-structured populations of $P$. spumarius. Interestingly, with the exception of Erigeron spp. and Chenopodium spp., found infected in late autumn, none of the other host plants in the Apulia Region have been found infected by X. fastidiosa ST53 so far. It is worth noting that, even if nymphs acquire the pathogen, they will lose pathogen and infectivity through molting, and therefore, newly emerged adults are Xylella free and must feed on an infected plant to become infectious (Almeida et al. 2005).

The wide polyphagy of $P$. spumarius is well known (Weaver and King 1954, Ossiannilsson 1981, Cornara et al. 2018), but host plant selection and host plant preference in open field conditions have 
been rarely investigated using a rational approach (see Halkka et al. 1967). The present study investigated host plant selection under real field conditions in the olive groves rather than host plant preference, as determined under controlled conditions using choice tests. Host plant selection was driven by host plant compositions in the different olive groves we inspected, and thus our results reflected the plant taxa actually exploited by spittlebug nymphs under the peculiar conditions of the investigated areas. This could explain the strong differences in host plant selection between our study and the results reported by Halkka et al. (1967).

Host plant selection by P. spumarius and other spittlebug species is still unclear, probably being influenced by multiple factors, e.g., internal factors in the plants (e.g., amino acids concentration, availability of water; Weaver and King 1954, Horsfield 1978, Thompson 1994), mechanical or ecological barriers (the presence of trichomes or lignified tissues; Hoffman and McEvoy 1985; McEvoy 1986). $P$. spumarius nymphs seem indeed to prefer tender shoots, possibly not distant from the apical buds, and their number appears to be correlated with xylem-sap nutrient content (Weaver and King 1954, Wiegert 1964). However, spatial conformation of the plant is also crucial, being leaf axils preferred over the stems, providing better shelter and permitting the formation of bigger foams by nymphs, thus increasing the protection from both natural enemies and desiccation (McEvoy 1986). It is out of the scope of our study to investigate on these determinants; nonetheless, our results, highlighting some clear host plant selection and avoidance by P. spumarius nymphs, suggest the need of further research on this topic.

The maximum population level of spittlebug nymphs measured in the three olive groves located inside the infected area was estimated in a range of 10-40 nymphs of $P$. spumarius per square meter, whereas the populations of $N$. campestris were much lower, with a peak of one to seven nymphs per square meter. Indeed, the meadow spittlebug can be present in high densities inside olive groves, and if we consider its role as a vector of X. fastidiosa, its abundance can explain why the disease has spread so fast in the area. In this context, it is interesting to note the higher plant infestation rate recorded in olive groves located in Lecce province compared with the ones located in Bari province. Lower populations of the vector north of the infected area may contribute to slow down the $X$. fastidiosa spread. However, these are preliminary data based only on spittle counts, and they should be confirmed by ad hoc estimation of vectors' population abundances.

Our study shows the high polyphagy and population levels of the principal vector of X. fastidiosa in Apulia, P. spumarius, pointing out the urgent need of control measures, like the ones that are mandatory to suppress nymph population by soil tilling (http://www.emergenzaXylella.it/portal/portale_gestione_agricoltura/Documenti/ lineeGuida). If such a nymph population is left undisturbed, a high number of adults will emerge and move to the olive canopies, where they can acquire and transmit the pathogen (Cornara et al. 2017a,b). A correct timing of soil tilling to prevent the emergence of adults is of key importance, and our data suggest that this measure should be applied in correspondence to the peak of nymphal populations (i.e., mid-April) and, before the emergence of adults, to achieve the maximum efficacy.

A better knowledge of the mechanisms influencing plant choice by the vectors of $X$. fastidiosa could help in developing effective management strategies, such as modifications in plant communities present inside and around olive groves to limit the vectors' population abundance. The application of agronomic measures that favor gramineous over dicotyledonous herbaceous plants should help in suppressing $P$. spumarius population. Although gramineous plants can favor the development of $N$. campestris, this latter species seems to be of minor importance in the disease spread, as it is rarely found on the olive canopy. Moreover, the knowledge of plant community of the olive grove and of host plant selection by the vector provides hints on the potential development of high populations of $P$. spumarius at specific sites.

\section{Supplementary Data}

Supplementary data are available at Journal of Economic Entomology online.

\section{Acknowledgments}

This research was supported in part by grant from the Horizon 2020 Framework Program under grant agreement no. 635646 'Pest Organisms Threatening Europe POnTE'.

\section{References Cited}

Almeida, R. P. P., M. J. Blua, J. O. R. S. Lopes, and A. H. Purcell. 2005. Vector transmission of Xylella fastidiosa: applying fundamental knowledge to generate disease management strategies. Annu. Entomol. Soc. Am. 96: 775-786.

Ben Moussa, I. E., V. Mazzoni, F. Valentini, T. Yaseen, D. Lorusso, S. Speranza, M. Digiaro, L. Varvaro, R. Krugner, and A. M. D’Onghia. 2016. Seasonal fluctuations of sap-feeding insect species infected by Xylella fastidiosa in Apulian olive groves of southern Italy. J. Econ. Entomol. 109: 1512-1518.

Bodino, N., E. Plazio, L. Picciau, V. Cavalieri, C. Dongiovanni, M. Di Carolo, D. Tauro, S. Volani, M. Salerno, V. Russo, et al. 2017. Phenology population dynamics and host plants of Philaenus spumarius in Italian olive groves, 19-20. In Proceedings, European Conference on Xylella 2017, 1315 November 2017, Universitat de les Illes Balears, Palma de Mallorca, Spain.

Borges, P. A. V., A. S. B. Rodrigues, S. E. Silva, S. G. Seabra, O. S. Paulo, and J. A. Quartau. 2018. New data on polymorphism of the meadow spittlebug Philaenus spumarius (L.) (Hemiptera: Aphrophoridae) from the island of São Miguel (Azores). Zootaxa 4369: 144-150.

Cavalieri, V., C. Dongiovanni, D. Tauro, G. Altamura, M. Di Carolo, G. Fumarola, M. Saponari, and D. Bosco. 2018. Transmission of the CODIRO strain of Xylella fastidiosa by different insect species, 144-145. In Proceedings, XI European Congress of Entomology, 2-6 July 2018, PagePress Publications, Voghera (PV), Italy.

Chen, X., V. B. Meyer-Rochow, A. Fereres, M. Morente, and A.-P. Liang. 2018. The role of biofoam in shielding spittlebug nymphs (Insecta, Hemiptera, Cercopidae) against bright light. Ecol. Entomol. 43: 273-281.

Cornara, D., V. Cavalieri, C. Dongiovanni, G. Altamura, F. Palmisano, D. Bosco, F. Porcelli, R. P. P. Almeida, and M. Saponari. 2017a. Transmission of Xylella fastidiosa by naturally infected Philaenus spumarius (Hemiptera, Aphrophoridae) to different host plants. J. Appl. Entomol. 141: 80-87.

Cornara, D., M. Saponari, A. R. Zeilinger, A. de Stradis, D. Boscia, G. Loconsole, D. Bosco, G. P. Martelli, R. P. P. Almeida, and F. Porcelli. 2017b. Spittlebugs as vectors of Xylella fastidiosa in olive orchards in Italy. J. Pest Sci. 90: 521-530.

Cornara, D., D. Bosco, and A. Fereres. 2018. Philaenus spumarius: when an old acquaintance becomes a new threat to European agriculture. J. Pest Sci. 91: 957-972.

de Jong, Y., Verbeek, M., Michelsen, V., Per de Place, B., Los, B., Steeman, F., Bailly, N., Basire, C., Chylarecki, P., Stloukal, E., Hagedorn, G., Wetzel, F.T., Glöckler, F., Kroupa, A., Korb, G., Hoffmann, A., Häuser, C., Kohlbecker, A., Müller, A., Güntsch, A., Stoev, P., and L. Penev. 2014. Fauna Europaea - all European animal species on the web. Biodivers. Data J. 2: e4034.

Drosopoulos, S. 2003. New data on the nature and origin of colour polymorphism in the spittlebug genus Philaenus (Hemiptera: Aphorophoridae). Ann. Soc. Entomol. Fr. NS 39: 31-42. 
EFSA Panel on Plant Health (PLH). 2015. Scientific opinion on the risks to plant health posed by Xylella fastidiosa in the EU territory, with the identification and evaluation of risk reduction options. EFSA J. 13: 3989-4251, 262.

EFSA Panel on Plant Health (PLH). 2018. Xylella fastidiosa pest categorization. EFSA J. 16(7): 5357, 61.

Elbeaino, T., T. Yaseen, F. Valentini, I. E. B. Moussa, V. Mazzoni, and A. M. D'Onghia. 2014. Identification of three potential insect vectors of Xylella fastidiosa in southern Italy. Phytopathol. Mediterr. 53: 328 .

Giampetruzzi, A., M. Saponari, G. Loconsole, D. Boscia, V. N. Savino, R. P. P. Almeida, S. Zicca, B. B. Landa, C. Chacón-Diaz, and P. Saldarelli. 2017. Genome-wide analysis provides evidence on the genetic relatedness of the emergent Xylella fastidiosa genotype in Italy to isolates from Central America. Phytopathology 107: 816-827.

Halkka, O., M. Raatikainen, A. Vasarainen, and L. Heinonen. 1967. Ecology and ecological genetics of Philaenus spumarius (L.) (Homoptera). Ann. Zool. Fenn. 4: 1-18.

Halkka, O., M. Raatikainen, L. Halkka, and T. Raatikainen. 1977. Coexistence of four species of spittle-producing Homoptera. Ann. Zool. Fenn. 14: 228-231.

Hill, B., and A. Purcell. 1995. Acquisition and retention of Xylella fastidiosa by an efficient vector, Graphocephala atropunctata. Phytopathology 85: 209-212.

Hoffman, G. D., and P. B. McEvoy. 1985. Mechanical limitations on feeding by meadow spittlebugs Philaenus spumarius (Homoptera: Cercopidae) on wild and cultivated host plants. Ecol. Entomol. 10: 415-426.

Horsfield, D. 1978. Evidence for xylem feeding by Philaenus spumarius (L.) (Homoptera: Cercopidae). Entomol. Exp. Appl. 24: 95-99.

Manly, B. F. J., A. J. Davis, L. L. McDonald, and D. L. Thomas. 1994. Resource selection by animals: statistical design and analysis for field studies. J. Anim. Ecol. 63: 745.

McEvoy, P. B. 1986. Niche partitioning in spittlebugs (Homoptera: Cercopidae) sharing shelters on host plants. Ecology 67: 465-478.

Nickel, H., and J. Hildebrandt. 2003. Auchenorrhyncha communities as indicators of disturbance in grasslands (Insecta, Hemiptera): a case study from the Elbe flood plains (northern Germany). Agric. Ecosyst. Environ. 98: 183-199.

Nickel, H., and R. Remane. 2002. Check list of the planthoppers and leafhoppers of Germany, with notes on food plants, diet width, life cycles, geographic range and conservation status (Hemiptera, Fulgoromorpha and Cicadomorpha). Beitr. Zikadenkunde 5: 27-64.
Ossiannilsson, F. 1981. The Auchenorrhyncha (Homoptera) of Fennoscandia and Denmark, part 2: the families Cicadidae, Cercopidae, Membracidae, and Cicadellidae (excl. Deltocephalinae). Fauna Entomol. Scand. 72: 225-252.

Pignatti, S. 1997. Flora d'Italia. Vol. I, II and III. Edagricole, Bologna, Italy.

R Core Team. 2017. R: a language and environment for statistical computing. R Foundation for Statistical Computing, Vienna, Austria.

Redak, R. A., A. H. Purcell, J. R. Lopes, M. J. Blua, R. F. Mizell 3rd, and P. C. Andersen. 2004. The biology of xylem fluid-feeding insect vectors of Xylella fastidiosa and their relation to disease epidemiology. Annu. Rev. Entomol. 49: 243-270.

Rodrigues, A. S., S. E. Silva, E. Marabuto, D. N. Silva, M. R. Wilson, V. Thompson, S. Yurtsever, A. Halkka, P. A. Borges, J. A. Quartau, et al. 2014. New mitochondrial and nuclear evidences support recent demographic expansion and an atypical phylogeographic pattern in the spittlebug Philaenus spumarius (Hemiptera, Aphrophoridae). PLoS One 9: e98375.

Saponari, M., G. Loconsole, D. Cornara, R. K. Yokomi, A. De Stradis, D. Boscia, D. Bosco, G. P. Martelli, R. Krugner, and F. Porcelli. 2014. Infectivity and transmission of Xylellua fastidiosa by Philaenus spumarius (Hemiptera: Aphrophoridae) in Apulia, Italy. J. Econ. Entomol. 107: 1316-1319.

Thompson, V. 1994. Spittlebug indicators of nitrogen-fixing plants. Ecol. Entomol. 19: 391-398.

Vilbaste, J. 1982. Preliminary key for the identification of the nymphs of North European Homoptera Cicadinea. II. Cicadelloidea. Ann. Zool. Fennici 19: $1-20$.

Weaver, C., and D. King. 1954. Meadow spittlebug Philaenus leucophthalmus (L.). Ohio Agric. Exp. Stn. Res. Bull. 741: 1-99.

Whittaker, J. B. 1970. Cercopid spittle as a microhabitat. Oikos 21: 59.

Whittaker, J. B. 1973. Density regulation in a population of Philaenus spumarius (L.) (Homoptera: Cercopidae). J. Anim. Ecol. 42: 163.

Whittaker, J. B., and N. P. Tribe. 1998. Predicting numbers of an insect (Neophilaenus lineatus: Homoptera) in a changing climate. J. Anim. Ecol. 67: 987-991.

Wiegert, R. G. 1964. Population energetics of meadow spittlebugs (Philaenus spumarius L.) as affected by migration and habitat. Ecol. Monogr. 34: 217-241.

Witsack, W. 1973. Experimental and ecological investigations on forms of dormancy in Homoptera-Cicadina (Auchenorrhyncha). 2. On ovarian parapause and obligatory embryonic diapause in Philaenus spumarius (L.) (Aphrophoridae). Zool. Jahrb. Abt. Für Syst. Okologie Geogr. Tiere. 100: 517-562. 